\title{
Rare variant of mixed total anomalous pulmonary venous connection
}

\author{
Jitendeep Singh, Prashant N. Mohite, Sandip Singh Rana \\ Department of Cardiothoracic and Vascular surgery, Post Graduation Institute of Medical \\ Education and Research, Chandigarh, India \\ Address for correspondence: Mr. Jitendeep Singh, Department of Cardiothoracic and Vascular surgery, \\ Post Graduation Institute of Medical Education and Research, Sector - 12, \\ Chandigarh - 160 012, India Email-jiten765@gmail.com
}

\begin{abstract}
Mixed variety of Total anomalous pulmonary venous connection is a rare congenital heart disorder with a wide variation of pulmonary venous anatomy and their drainage. Present article depicts " $3+1$ " variant of mixed TAPVC treated by rechannelizing all pulmonary veins to left atrium using a Polytetrafleuroethylene patch.
\end{abstract}

Key words: Mixed total anomalous pulmonary venous connection, total anomalous pulmonary venous connection, polytetrafleuroethylene patch

\section{INTRODUCTION}

Total anomalous pulmonary venous connection (TAPVC) develops when the primordial pulmonary vein fails to unite with the plexus of veins surrounding the lung buds. In 1959, Darling and associates ${ }^{[1]}$ proposed a classification, also based on the anatomy of the anomalous connection. Four types were identified: type 1 , anomalous connection at the supracardiac level; type 2, anomalous connection at the cardiac level; type 3 , anomalous connection at the infracardiac level; and type 4, anomalous connection at two or more of the above levels. Mixed TAPVC (type 4) is a rare condition, accounting for only $5 \%$ of diagnosed TAPVC. ${ }^{[2]}$ It is associated with a poor prognosis unless surgically corrected by connecting the pulmonary venous sinus to the left atrium. We report a " $3+1$ " variant of mixed TAPVC treated by rechannelizing all pulmonary veins

\begin{tabular}{|l|l|}
\hline \multicolumn{2}{|c|}{ Access this article online } \\
\hline Quick Response Code: & Website: \\
\hline & \\
\cline { 2 - 2 } & \\
\hline
\end{tabular}

to left atrium using a polytetrafleuroethylene (PTFE) patch.

\section{CASE REPORT}

A 10-year-old male child came with the chief complaints of bluish discoloration of lips and tongue since birth. He had repeated respiratory tract infections since 6 months of age and developed dyspnoea on exertion, grade III. On examination, the lips, tongue, and nails were light blue with second degree clubbing. Ejection systolic murmur was heard all over the precordium and prominent on pulmonary area. The room air oxygen saturation was $85 \%$. The ECG showed right bundle branch block and X-ray chest showed cardiomegaly with pulmonary plethora. The echocardiography showed pulmonary veins opening at the junction of superior venacava (SVC) and right atrium with osteum secondum atrial septal defect of $16 \mathrm{~mm}$. The catheterization was done for further evaluation, which showed similar findings with normal pulmonary artery pressure and step up of oxygen saturation with $25 \%$ at the junction of SVC and right atrium.

Patient was taken up for surgery with median sternotomy approach. Right atrium and SVC was grossly dilated. 
The right upper pulmonary vein was opening into SVC just below the entry of azygous vein. The right inferior, left superior, and left inferior pulmonary veins were forming a common chamber just behind the junction of SVC and right atrium, which was opening into right atrium without forming a vertical vein [Figure 1]. After standard aortic cannulation, SVC was cannulated above the opening of anomalous right superior pulmonary vein and inferior venacava at its junction with right atrium. Patient was put on cardiopulmonary bypass, aorta cross clamped and heart arrested. Right atriotomy, extending $1 \mathrm{~cm}$ over the SVC, was made, which revealed osteum secondum defect and an opening of common chamber at SVC-RA (superior vana cava - right atrial) junction. The draining orifice of right superior pulmonary vein was noticed on lateral aspect of SVC just below the azygous entry. Atrial septal defect was enlarged in the direction of opening of common chamber. A longitudinal PTFE patch was designed and sutured over the floor of right atrium in such a way that openings of all the pulmonary veins were diverted to left atrium through atrial septal defect [Figure 2]. Coronary sinus was left in right atrium. SVC and right atrium were enlarged using a lenticular shaped pericardial patch to ensure its unobstructed flow. The patient was extubated after $12 \mathrm{~h}$ and could maintain $100 \%$ saturation on room air, shortly. The postoperative recovery was uneventful.

\section{DISCUSSION AND CONCLUSION}

TAPVC is a rare congenital anomaly, corresponding to approximately $2 \%$ of all congenital heart defects. ${ }^{[2]}$ It consists of an abnormality of blood flow in which all four pulmonary veins drain into systemic veins or

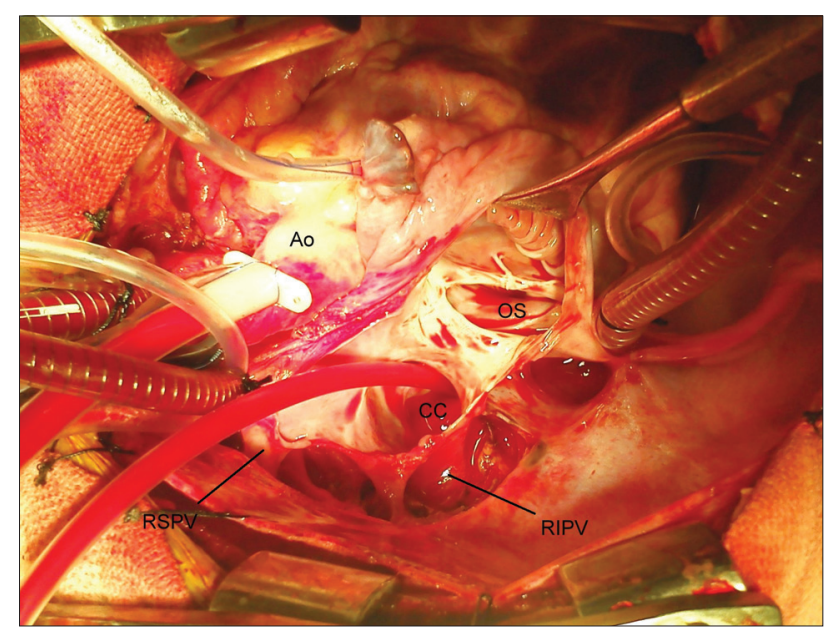

Figure 1: Opened right atrium showing common chamber and ostium secondum atrial septal defect. Right superior pulmonary vein, right inferior pulmonary vein the right atrium with or without pulmonary venous obstruction. ${ }^{[3]}$ Failure of the common pulmonary vein to connect with the pulmonary venous plexus leads to persistence of one or more earlier venous connections to the right SVC, to the left vertical vein/innominate vein, or to the umbilicovitelline vein/portal vein. ${ }^{[4]}$

According to Darling's classification of this disorder, type IV or mixed type (5\% of the cases), unlike the others, is characterized by the lack of confluence of the pulmonary veins into a vertical collecting vein. ${ }^{[1]}$ Mixed variety is further surgically classified into two groups; " $3+1$ " pattern, in which three veins drain at the cardiac level or in the vertical vein and the other in another site and " $2+2$ " pattern, in which the veins from each lung unite and then drain in different sites ${ }^{[5]}$ In most cases, the veins of one lung drain at the cardiac level and from the other at the supracardiac level.$^{[6,7]}$ In the present article, the pattern was " $3+1$," that is, right upper pulmonary vein was draining into SVC while rest of the veins were forming a common chamber which was opening into right atrium at the junction of SVC and right atrium.

Though echocardiography is sufficient for diagnosing most of the cases of TAPVC, cardiac catheterization is essential in mixed variety to delineate anatomy, drainage, and obstruction of all four pulmonary veins, measuring PAP in late presenters, to determine the etiology of systemic arterial desaturation, and to assess the presence of suspected major associated cardiac anomalies. ${ }^{[5,8]}$ Apical and subcostal 4-chamber echocardiographic views usually best identify individual pulmonary veins and their confluence. ${ }^{[9,10]}$ The correct preoperative diagnosis and an accurate anatomic description are essential for planning surgical treatment of these patients. The goal

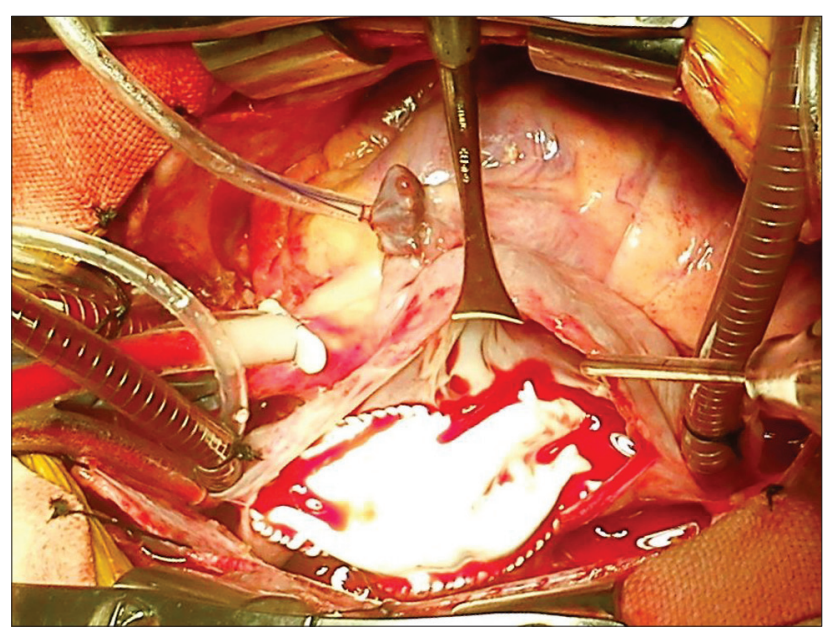

Figure 2: Polytetrafleuroethylene patch directing all pulmonary veins to left atrium through atrial septal defect 
of surgery is to redirect all pulmonary veins to the left atrium through wide and nonrestrictive connection. Careful intraoperative examination of the pulmonary venous drainage is mandatory for all patients. Because of the wide anatomic variations in mixed variety of TAPVC, various techniques and modifications have been published in the literature. In " $3+1$ " pattern, when the common drainage site of three pulmonary veins is in the coronary sinus, vertical vein, or at the infradiaphragmatic level, rechanneling of the confluence is easily performed while the drainage of the rest pulmonary vein is individually tailored, ${ }^{[8]}$ but the precise technique adopted in an individual patient depends on the pattern of anatomic drainage, and an individualized surgical approach is recommended. In the present article, pulmonary venous flow from all pulmonary veins was rechannelized to left atrium using a single PTFE patch using van Son's technique. ${ }^{[11]}$ Mortality after TAPVC repair has decreased but remains highest in young patients and in those with cardiac connection type or pulmonary venous obstruction despite improved perioperative care. ${ }^{[12]}$ Surgical mortality remains higher in repair of mixed form of TAPVC, especially in patients with more complex patterns of pulmonary venous connection. Patients with " $3+1$ " variety have higher risk for surgery than a " $2+2$ " pattern of mixed totally anomalous pulmonary venous connection..$^{[8]}$

\section{REFERENCES}

1. Darling RC, Rothney WB, Craig JM. Total pulmonary venous drainage into the right side of the heart: report of 17 autopsied cases not associated with other major cardiovascular anomalies. Lab Invest 1957;6:44-64.

2. Bharati S, Lev M. Congenital anomalies of the pulmonary veins.
Cardiovasc Clin 1973;5:23-41.

3. Emmanouilides GC, Gutgesell HP, Riemenschneider TA, Allen HD,. Moss and Adams Heart Disease in Infants, Children and Adolescents: Including the Fetus and Young Adult. $5^{\text {th }}$ ed.Philadelphia .Lippincott Williams \& Wilkins. 1995.

4. Neill CA. Development of the pulmonary veins; with reference to the embryology of anomalies of pulmonary venous return. Pediatrics 1956;18:880-7.

5. Delius RE, de Leval MR, Elliot MJ, Stark J. Mixed total pulmonary venous drainage: still a surgical challenge. J Thorac Cardiovasc Surg 1996;112:1581- 8 .

6. Thompson LD, McElhinney DB, Reddy VM, Jue KL, Hanley FL. Infradiaphragmatic totally anomalous pulmonary venous return with two separate descending veins in association with right atrial isomerism. Ann Thorac Surg 2000;70:1400-2.

7. Sarioglu T, Kinoglu B, Paker T, Sarioglu A, Saltik L, Aytaç A. A rare case of mixed type total anomalous pulmonary venous connection and its surgical treatment. Thorac Cardiovasc Surg 1997;45:152-4.

8. Chowdhury UK, Airan B, Malhotra A, Bisoi AK, Saxena A, Kothari SS. Mixed total anomalous pulmonary venous connection: anatomic variations, surgical approach, techniques, and results. J Thorac Cardiovasc Surg 2008;135:106-16, 116.e1-5.

9. Huhta JC, Gutgesell HP, Nihill MR. Cross sectional echocardiographic diagnosis of total anomalous pulmonary venous connection. Br Heart J. 1985;53:525-34.

10. Van Der Velde ME, Parness IA, Colan SD, Spevak PJ, Lock JE, Mayer JE Jr, et al. Two-dimensional echocardiography in the pre and postoperative management of totally anomalous pulmonary venous connection. J Am Coll Cardiol 1991;18:1746-51.

11. van Son JA, Danielson GK, Puga FJ, Edwards WD, Driscoll DJ. Repair of congenital and acquired pulmonary vein stenosis. Ann Thorac Surg 1995;60:144-50.

12. Karamlou T, Gurofsky R, Al Sukhni E, Coles JG, Williams WG, Caldarone $\mathrm{CA}$, et al. Factors associated with mortality and reoperation in 377 children with total anomalous pulmonary venous connection. Circ 2007;115:1591-8.

How to cite this article: Singh J, Mohite PN, Rana SS. Rare variant of mixed total anomalous pulmonary venous connection. J Cardiovasc Dis Res 2012;3:248-50.

Source of Support: Nil, Conflict of Interest: None declared. 